\title{
Impact of body composition changes on risk of all-cause mortality in older adults
}

Christophe E. Graf ${ }^{1} \mathrm{MD}$, François. R. Herrmann ${ }^{1} \mathrm{MD} \mathrm{MPh}$, Adrian Spoerri ${ }^{2} \mathrm{PhD}$, Anne-Marie Makhlouf ${ }^{3}$ BSc, Thorkild I.A. Sørensen MD ${ }^{4,5,6}$, Sylvain Ho ${ }^{2}$ Bsc, Véronique L. Karsegard Bsc ${ }^{3}$, Laurence Genton ${ }^{3} \mathrm{MD}$

${ }^{1}$ Division of Geriatrics, Dept. Internal Medicine, Rehabilitation and Geriatrics, Geneva University Hospitals and University of Geneva, Geneva, Switzerland

${ }^{2}$ Institute of Social and Preventive Medicine, University of Bern, Bern, Switzerland

${ }^{3}$ Clinical Nutrition, Geneva University Hospitals, Geneva, Switzerland

${ }^{4}$ Institute of Preventive Medicine, Bispebjerg and Frederiksberg Hospital, Copenhagen, Denmark

${ }^{5}$ Novo Nordisk Foundation Center for Basic Metabolic Research, Section on Metabolic Genetics, Faculty of Medical and Health Sciences, University of Copenhagen, Denmark

${ }^{6}$ MRC Integrative Epidemiology Unit, Bristol University, Bristol, UK

Date: 7 September 2017

Article content: 3179 words, 3 tables, 1 figure

Keywords: body composition, fat mass index, fat-free mass index, mortality

Correspondence and reprint requests to:

Laurence Genton, MD, Clinical Nutrition

Rue Gabrielle Perret-Gentil 4, Geneva University Hospitals, 1211 Geneva 14, Switzerland

Phone: +41 / 223729344 Fax: +41 / 223729363

E-mail: laurence.genton@hcuge.ch

Short running title: Changes in body composition and mortality among older people

\section{ABSTRACT}


Purpose: This study evaluates the relationship between body mass index (BMI), fat mass index (FMI) and fat-free mass index (FFMI) changes and mortality in persons $\geq 65$ years.

Methods: Adults $\geq 65$ years with at least two body composition measurements (BCM) between 1990 and 2011 were included. We excluded persons who died within one month of the second $\mathrm{BCM}$ and who had two single BCM in a one-month timeframe. Mortality data was retrieved until December 2012. For each person, we calculated the regression slopes for BMI, FMI and FFMI changes. Significant positive slopes were categorized as "gain", negative slopes as "loss" and the others as "maintenance". The impact of body composition changes was evaluated by Cox regression models while adjusting for sex, age, co-morbidities and body composition at the last measurement.

Results: We included 791 persons with 3049 BCM. After adjustment for sex, and age and comorbidities, a loss of FFMI, but not of FMI or BMI, increased the risk of mortality (HR 2.02, 95\%CI 1.28-3.19). The prediction of mortality with FFMI loss remained significant when further adjusting for FMI loss and the last available body composition (HR 1.68, 95\%CI 1.04- 2.70). Conclusions: FFMI loss is related to increased mortality in older persons. 


\section{INTRODUCTION}

In older persons, body mass index (BMI), corresponding to height-adjusted weight, is associated to mortality through a U-shaped or reverse J-shaped curve (1-3). Considering that BMI consists of fat mass (FM) and fat-free mass (FFM), several cohort studies tried to identify whether FM or FFM predicted mortality. They reported either no impact $(4,5)$ or an increased mortality with low FFM (6-8) and high FM (8-10). These discrepancies may be due to methodological issues, but could also indicate that mortality is better predicted by changes in weight and body composition than absolute values.

Weight loss has been associated with increased risk of mortality in patients with chronic heart failure (11), cancer (12, 13), Alzheimer's disease (14), chronic kidney failure (15), chronic obstructive pulmonary disease (16) and amyotrophic lateral sclerosis (17). In older persons specifically, weight loss predicts mortality, even though the studies differ regarding the amount and the considered timeframe of weight loss, and the time of follow-up between weight loss assessment and mortality (18-21). One study has evaluated the relation between body composition changes and mortality in older persons and was performed in ambulatory US residents. It showed an increased risk of death in men who had lost $\geq 5 \%$ body weight, lean body mass, appendicular lean mass or fat mass over an average of 4.6 years (22). Since the study included only men, it is not clear whether these findings also apply to women.

The question whether loss of FM or FFM in older persons increases the risk of mortality is important in order to target therapeutic strategies. The loss of FM can theoretically be prevented by hypercaloric diets, while the loss of FFM can be limited by appropriate calorie and protein intakes (23) and the addition of physical activity $(13,24)$. Furthermore, if the loss of both FM and FFM increases the risk of mortality in older persons, it would suggest that any hypocaloric diet, even voluntary, should be avoided in these persons.

This study aimed at exploring the relationship between weight and body composition (BC) changes and all-cause mortality in men and women aged over 65 years. 


\section{METHODS}

\section{Subjects and design}

This historical cohort study includes all subjects aged $\geq 65$ years, who had at least two measurements of body composition by $50-\mathrm{kHz}$ bioimpedance analysis (BIA), performed between January 1990 and December 2011, at the Geneva University Hospitals (HUG). Persons were measured in clinical routine or in a research setting.

Persons were excluded if 1) they were living outside of Switzerland, because we could not obtain mortality data, 2) they had undergone only two BIA measurements in a timeframe $<1$ month, because small differences in such a short time may reflect changes in hydration status rather than body composition, and 3) they had undergone only two BIA measurements, with the second measurement within one month of death, because the latter measurement could be affected by the terminal phase of life per se, 4) they had negative FM, probably due to fluid and electrolyte abnormalities not identified by the nutrition team and which limit the accuracy of BIA measurements, and 5) their co-morbidities and lifestyle habits at the time of the last body composition measurement were not known, precluding the calculation of a co-morbidity score. This protocol was approved by the Ethical Committee of the HUG who waived the requirement for a signed informed consent. It was registered under clinicaltrials.gov (NCT01472679).

\section{Body composition and co-morbidities}

We retrieved the BIA parameters $(50-\mathrm{kHz}$ resistance, reactance), anthropometric data, comorbidities and lifestyle habits at the time of body composition measurements, from two sources: 1) the computer database of the HUG for measurements performed in clinical routine since 2000 and 2) the database of the nutrition unit of the HUG for measurements performed in clinical routine from 1990 to 1999 and in research setting from 1990 to 2011 (7). As detailed elsewhere (7), BIA measurements are performed in our institution, in hospitalized and ambulatory patients at nutritional risk, in order to follow their nutritional state and potentially adapt their nutritional 
support. The BIA measurements in the research setting were performed mostly in healthy persons in order to create a population-specific BIA formula and normative values according to age and physical activity.

Measurements of weight, height and resistance and reactance by $50-\mathrm{kHz}$ BIA are standardized in the HUG, and have been described previously (25). These parameters were introduced into the Geneva formula, developed (26) and validated against dual-energy x-ray absorptiometry (27) in older persons living in the Geneva area, in order to obtain FFM. FM was calculated as body weight $(\mathrm{kg})$ minus FFM (kg). FM and FFM were divided by height $\left(\mathrm{m}^{2}\right)$ to obtain fat-free mass index (FFMI) and fat mass index (FMI).

We used several BIA devices over the 21 years: RJL-109 and RJL-101 (RJL Systems, Inc., Clinton Towhnship MI, USA), Xitron 4000 B (Xitron Technologies, San Diego, CA, USA), BioZ2 (Spengler, Paris, France), and Nutriguard (Data Input GmbH, Darmstadt, Germany). All BIA devices were calibrated using a calibration jig, setting a limit of tolerance, at $50 \mathrm{kHz}$, of $5 \Omega$ for impedance and 2 degrees for the phase angle. For FFM, the method agreement in vivo, calculated from 53 paired measurements, was $0.03 \mathrm{~kg}$ (95\% confidence interval (CI): -1.7 to $2.1 \mathrm{~kg}$ ), and the inter-observer agreement, determined in 51 persons, was $0.02 \mathrm{~kg}$ (95\% CI -1.3 to 1.3 ) (25).

We relied on the letters of admission or discharge, or the consultations reports to determine comorbidities and lifestyle habits at the time of body composition measurements. This data was translated into a score, using the modified Cumulative Illness Rating Scale (CIRS) (28). CIRS evaluates 14 organs and systems, and assigns each of them a score from 0 (no disease) to 4 (severe disease) points. CIRS has been positively associated with mortality (29). In our study, the Spearman correlation between the two raters who determined retrospectively the CIRS was 0.92, based on the CIRS of 20 randomly selected persons.

\section{Mortality}

Mortality data was retrieved until December 2012 from the computer database of the HUG, the 
Geneva population register of deaths (30), and the Swiss National Cohort (SNC) (31), as explained elsewhere (7). The latter is a national data platform which associates anonymously allcause and cause-specific mortality to national censuses.

\section{Statistical analyses}

Characteristics of the included persons at the last BIA measurement are presented as means \pm standard deviation. We checked the normality of the distribution of continuous data by ShapiroWilks tests. Data between women and men and between included persons and those excluded on the basis of missing CIRS were compared by unpaired t-tests for continuous variables and MannWhitney u tests for categorical variables. Significance, set originally at $\mathrm{p}<0.05$, was corrected to $\mathrm{p}<0.04$ for multiple analysis according to the Benjamini-Hochberg method (32).

The BMI at the last body composition measurement was categorized as $<18.5 \mathrm{~kg} / \mathrm{m}^{2}, 18.5-24.9$ $\mathrm{kg} / \mathrm{m}^{2}$ and $>25 \mathrm{~kg} / \mathrm{m}^{2}$, because the association between BMI and mortality is U-shaped or Jshaped. The category $>25 \mathrm{~kg} / \mathrm{m}^{2}$ included patients of the WHO categories 25.0-29.9, 30.0-34.9, and $\geq 35.0 \mathrm{~kg} / \mathrm{m}^{2}$ (33). The FFMI at the last body composition measurement was dichotomized into absence or presence of sarcopenia (FFMI $<15.1 \mathrm{~kg} / \mathrm{m}^{2}$ for women and $<17.5 \mathrm{~kg} / \mathrm{m}^{2}$ for men) and the last FMI into absence or presence of obesity (FMI $>8.2 \mathrm{~kg} / \mathrm{m}^{2}$ for women and $>5.2 \mathrm{~kg} / \mathrm{m}^{2}$ for men) (34). The choice of categorization of last BMI, FFMI and FMI data, as compared to the use of continuous values, quadratic $\left(\mathrm{BMI}+\mathrm{BMI}^{2}\right)$ or cubic splines $\left(\mathrm{BMI}+\mathrm{BMI}^{2}+\mathrm{BMI}^{3}\right)$, relies on two elements. First, the explained variation of mortality $\left(\mathrm{R}^{2}\right)(35)$ in unadjusted cox regression models is best with BMI and FFMI categories (supplemental table 1). Second, the categorizations provide more explicit data for the clinician than quadratic or cubic splines. Thus, although, the quadratic spline provides the best $\mathrm{R}^{2}$ for FMI, we preferred categorizing the last BMI and body composition.

To evaluate the impact of body composition changes on mortality using all available measurements, we calculated, for each person, the regression slopes for BMI, FMI and FFMI 
changes over time and its significance. We categorized significantly positive $(\mathrm{p}<0.05)$ slopes as "gain", significantly negative slopes $(\mathrm{p}<0.05)$ as "loss" and the others as "maintenance". The characteristics of our study population at the last BIA measurement were compared between categories of BMI, FMI and FFMI changes by Kruskall-Wallis tests or Chi-squared tests, as appropriate. These models including the last assessment values and the changes which occurs before, explain the mortality risk of the patient we see today according to his/her current body composition and the way this risk is modified by our knowledge about the preceding changes in body composition.

We performed univariate Cox regressions, using days as time axis and counting deaths from one month after the last BIA measurement, to evaluate whether body composition changes predicted mortality, followed by 5 models of multiple Cox regressions. Model 1, 2 and 3 evaluated the impact of BMI, FFMI and FMI changes separately, with adjustments for age and CIRS at last BIA measurement and sex. Model 4 incorporated BMI changes and BMI at the last BIA measurement, with the same adjustments as before, while Model 5 incorporated FMI and FFMI changes and the body composition at the last BIA measurement. For each model, we reported hazard ratios (HR), 95\% CI and the level of significance. For each covariable, we plotted ln [$\ln$ (survival probality] vs. In (time) to verify the proportional hazard assumptions. To evaluate collinearity among covariates, we examined the variance inflation factor (VIF) for the covariates in the five multiple Cox regression models. As the VIF was below 5 for all covariates, there was no collinearity in any model. Interactions between sex and BMI or body composition changes were calculated in the Cox regression Models 4 and 5. Finally, we reported Kaplan-Meier curves for the categories of BMI, FFMI and FMI changes, calculated log rank tests to compare the curves and determined mortality trends throughout the categories of BMI, FFMI and FMI changes.

Significance was set at $\mathrm{p}<0.05$. Statistical analyses were run with Stata software version 13.1 (TX, USA). 


\section{RESULTS}

We included 791 persons (318 women and 473 men) totalizing 3049 BIA measurements. The trial flow-chart is shown on supplemental figure 1. Two hospitalized women were excluded because of negative FMI probably linked with hydro-electrolytic disturbances as one suffered from aggravation of chronic renal failure, and the other one of severe malnutrition. Persons excluded because of missing CIRS $(n=94)$ were younger and had a lower BMI and FMI at last BIA measurement than included persons (supplemental table 2).

The characteristics of the included persons at the last BIA measurement are shown on table $\mathbf{1}$. They had a median number of 3 BIA measurements in both gender (range: 2 to 24 in women; 2 to 27 in men). Expressed as median (range), the median duration between the first and last BIA measurement was $1.5(0.1$ to 12.9$)$ and $1.0(0.1$ to 11.0$)$ years in women and men, respectively, and the median time interval between BIA measurements was 0.5 years ( 1 day to 15.4 years) and 0.3 years ( 1 day to 14.3 years) in women and men, respectively. Categorization into BMI, FMI and FFMI changes highlight that BMI and body composition did not change significantly over time for the majority of the persons (table 2). Persons who had lost FMI were mostly non obese at the last BIA measurement, while those who had lost FFMI were mostly sarcopenic at the last BIA measurement (supplemental table 3).

Of the 791 persons, 425 persons $(58 \%)$ died. Causes of mortality, available in 382 persons, were cancer (29\%), cardiovascular diseases (22\%) and respiratory diseases (11\%). Univariate Cox regressions demonstrated that a loss of FFMI was related to an increased risk of mortality compared to a stable FFMI, while changes of FMI had no impact on mortality (supplemental table 4).

When adjusting for age and CIRS at last BIA measurement and sex, a loss of FFMI doubled the risk of mortality, but changes of FMI and BMI had no significant impact on mortality (table 3). The inclusion of BMI changes and last BMI into a single Cox regression model adjusted for sex, last age and last CIRS highlights that BMI changes still do not predict mortality (Model 4). 
However, when considering body composition changes and the last body composition instead of BMI changes and the last BMI (Model 5), a loss of FFMI was related to an increased risk of mortality by $68 \%$, while changes of FMI had no impact on mortality.

In Model 4, sex interacted significantly with BMI gain $(\mathrm{p}=0.001)$ but in Model 5, no significant interactions could be highlighted between sex and FFMI or FMI changes. Kaplan-Meier survival curves (figure 1) and mortality trends (supplemental table 5) for categories of BMI, FMI and FFMI changes were performed by sex. Kaplan-Meier curves showed that loss of BMI and FFMI were both associated with a worse survival. 


\section{DISCUSSION}

This study demonstrates that the majority of the studied older persons have a stable BMI, FMI and FFMI over time. However, those who are losing FFMI have a higher risk of mortality than those who are maintaining it, even when adjusting for co-morbidities and body composition at the last BIA measurement. In contrast, a loss of BMI or FMI has no impact on mortality in this older study population.

One study has evaluated the relationship between body composition changes and mortality in older persons. The authors measured body composition by dual-energy x-ray absorptiometry in 4331 ambulatory US men over 65 years, on two occasions, at a mean time interval of 4.6 years. Three years after the second visit, 433 men had died. Mortality was higher in men who had lost $\geq$ $5 \%$ body weight, lean body mass, appendicular lean mass or FM between both visits (22). Regarding lean body mass, this represented a median loss of - $0.07 \mathrm{~kg} / \mathrm{month}$ (range -0.09 to 0.06), as compared to a median loss of $-0.15 \mathrm{~kg}$ of FFM/month (range -0.69 to -0.01 ) in the men of this study. Although the extent of FFM loss predicting an increased risk of mortality varies, both studies agree that a loss of FFMI negatively affects survival.

However, our study does not support the negative impact of FMI loss. This difference may be due to several issues. First, we have included men and women in the same Cox regression model. This raises the question whether FMI loss has a different impact on mortality in men and women, but sex did not interact significantly with FMI loss. Second, the persons who have lost FMI may have started with a different baseline body composition. A lower baseline FFMI or FMI may have increased the risk of mortality. This data could not be retrieved in the study of Lee et al, precluding any comparison with our study. Third, our persons probably suffered from more comorbidities than those in the study of Lee et al, who underwent measurements only in the ambulatory setting. These co-morbidities may have obscured the impact of FMI loss alone. Fourth, differences may be due to methodological issues. Indeed, in our study we took into account more than 2 BIA measurements when available. Also, our methodology used for 
categorization of body composition changes resulted in a more severe threshold for the categorization in the group "FMI loss" than in the study by Lee et al. (median loss of FM: -0.17 vs. $-0.05 \mathrm{~kg} / \mathrm{month}$ in men) and in a smaller proportion of persons categorized in this group (6 vs. $31 \%$ of the study population). Finally, the adjustments performed in the Cox regressions differed. Thus, the impact of FMI loss on mortality needs further investigations and should probably include longitudinal measurements in the hospital and ambulatory setting to better capture body composition variations.

Several articles have evaluated the impact of weight loss in persons $>60$ years at baseline on mortality. In outpatients, mortality was predicted by a weight loss over $1 \mathrm{~kg}$ per year (18), over 1 $\mathrm{kg}$ in one year (19) or over $5 \%$ of initial body weight within 3 years (20). The reason why we could not confirm this finding in our study is unclear. It may be related to the consideration of body composition changes during a longer timeframe in our study, to the adjustment for baseline co-morbidities through the CIRS and to the evaluation of weight changes through $\geq 2$ measurements. The afore-mentioned studies have excluded patients with cancer, myocardial infarction, diabetes or stroke at baseline (18), or adjusted their results only for a very limited number of co-morbidities $(19,20)$. Also, in these studies, weight change relied only on two timepoints in contrast with our study, which may be misleading as a persont could be weight-stable using two time-points but still have gained or lost weight in between. Furthermore, none of these studies have evaluated whether the impact of weight loss differed according to baseline weight. Recent studies found no benefit of intentional weight loss on mortality in older overweight or obese persons, whether old (36) or young (36) (37) (38). In our study, $80 \%$ of the persons who had lost weight still had a BMI $\geq 25 \mathrm{~kg} / \mathrm{m}^{2}$ at last follow-up. Finally, as explained elsewhere (39), the consideration of weight changes does not capture the changes in regional body composition, which may be as important for prediction of mortality.

The originality of this study is to take into account BMI and body composition changes in older persons by considering more than two measurements, if available, which may better take into 
account intra-individual variations than two measurements. We have adjusted our regressions for the CIRS, which takes into account co-morbidities and lifestyle habits as smoking and alcohol at the last observation of the patients. Regarding the study limitations, our population was too small in some sub-categories (like BMI or body composition changes) for separate Cox regressions by sex and required pooling of men and women. This is due to the fact that Cox regressions are parametrical statistical tests, whereas the log rank tests used to compare Kaplan-Meyer curves are non parametric tests. However, the pooling had the advantage to highlight that body composition changes affected men and women differently. Furthermore, we have no indication on voluntary vs. involuntary weight loss. This information could be important as involuntary weight loss is associated with an increased risk of mortality. In contrast, voluntary weight loss has no impact on mortality risk overall, but subgroup analysis highlighted an increased risk in healthy obese persons and a decreased risk in unhealthy obese persons (40). However, this information cannot be integrated in our study design including several measurement as many people undergo over years episodes of involuntary weight loss, as for instance during episodes of hospitalization, and voluntary weight loss. Furthermore, we have not reported physical activity, which may be a confounding factor.

\section{CONCLUSION}

This study highlights the negative impact of FFMI loss on mortality in persons $\geq 65$ years, irrespective of sex, and age, co-morbidities, and body composition at the last follow-up. It could not confirm that loss of BMI or FMI were related to increased mortality. Future clinical and epidemiological studies should evaluate the impact of body composition and weight changes based on several measurements, and not on only two measurements, on mortality and evaluate whether maintaining FFMI over time with physical exercise or anabolic strategies may improve survival. 


\section{ACKNOWLEDGMENTS}

We thank the following people for their contributions: M. Gilles Cohen for exporting the medical data from the informatics database of the University Hospital of Geneva; Prof. Claude Pichard, MD, PhD (Clinical Nutrition, University Hospital of Geneva, Geneva, Switzerland) for his helpful comments during the preparation of the grant submission; Dr. Kurt Schmidlin (Institute of Social and Preventive Medicine, University of Bern, Bern, Switzerland) for performing the linkage to the SNC.

\section{FUNDING/SUPPORT}

This work was partly supported by the Research Fund of the Department of Internal Medicine of the University Hospital and the Faculty of Medicine of Geneva; this Fund receives and unrestricted grant from AstraZeneca Switzerland. It was awarded to Dr Genton. The SNC is funded by the Swiss National Science Foundation (grant number 33CSC0_134273).

\section{ABSTRACT PRESENTATION}

Part of this work has been submitted as an abstract to the congress of the European Society for Clinical Nutrition and Metabolism (ESPEN), which will be held in Lisbon in September 2015. 


\section{REFERENCES}

1. Singh PN, Haddad E, Tonstad S, Fraser GE. Does excess body fat maintained after the seventh decade decrease life expectancy? Journal of the American Geriatrics Society. 2011;59(6):1003-11. 2. Landi F, Onder G, Gambassi G, Pedone C, Carbonin P, Bernabei R. Body mass index and mortality among hospitalized patients. Archives of internal medicine. 2000;160(17):2641-4. 3. Flicker L, McCaul KA, Hankey GJ, Jamrozik K, Brown WJ, Byles JE, et al. Body mass index and survival in men and women aged 70 to 75 . Journal of the American Geriatrics Society. 2010;58(2):234-41.

4. Wannamethee SG, Shaper AG, Lennon L, Whincup PH. Decreased muscle mass and increased central adiposity are independently related to mortality in older men. The American journal of clinical nutrition. 2007;86(5):1339-46.

5. Bunout D, de la Maza MP, Barrera G, Leiva L, Hirsch S. Association between sarcopenia and mortality in healthy older people. Australasian journal on ageing. 2011;30(2):89-92.

6. Kuk JL, Ardern CI. Influence of age on the association between various measures of obesity and all-cause mortality. Journal of the American Geriatrics Society. 2009;57(11):2077-84.

7. Graf C, Karsegard VL, Spoerri A, Makhlouf A-M, Ho S, Herrmann FR, et al. Body composition and all-cause mortality in subjects older than $65 \mathrm{y}$. The American journal of clinical nutrition.101:760-7.

8. Bigaard J, Frederiksen K, Tjonneland A, Thomsen BL, Overvad K, Heitmann BL, et al. Body fat and fat-free mass and all-cause mortality. Obes Res. 2004;12(7):1042-9.

9. Bigaard J, Frederiksen K, Tjonneland A, Thomsen BL, Overvad K, Heitmann BL, et al. Waist circumference and body composition in relation to all-cause mortality in middle-aged men and women. International journal of obesity. 2005;29(7):778-84.

10. Allison DB, Zhu SK, Plankey M, Faith MS, Heo M. Differential associations of body mass index and adiposity with all-cause mortality among men in the first and second National Health 
and Nutrition Examination Surveys (NHANES I and NHANES II) follow-up studies. Int J Obes Relat Metab Disord. 2002;26(3):410-6.

11. Pocock SJ, McMurray JJ, Dobson J, Yusuf S, Granger CB, Michelson EL, et al. Weight loss and mortality risk in patients with chronic heart failure in the candesartan in heart failure: assessment of reduction in mortality and morbidity (CHARM) programme. European heart journal. 2008;29(21):2641-50.

12. Buskermolen S, Langius JA, Kruizenga HM, Ligthart-Melis GC, Heymans MW, Verheul HM. Weight loss of $5 \%$ or more predicts loss of fat-free mass during palliative chemotherapy in patients with advanced cancer: a pilot study. Nutrition and cancer. 2012;64(6):826-32.

13. Davidson W, Ash S, Capra S, Bauer J, Cancer Cachexia Study G. Weight stabilisation is associated with improved survival duration and quality of life in unresectable pancreatic cancer. Clinical nutrition. 2004;23(2):239-47.

14. White H, Pieper C, Schmader K. The association of weight change in Alzheimer's disease with severity of disease and mortality: a longitudinal analysis. Journal of the American Geriatrics Society. 1998;46(10):1223-7.

15. Usvyat LA, Barth C, Bayh I, Etter M, von Gersdorff GD, Grassmann A, et al. Interdialytic weight gain, systolic blood pressure, serum albumin, and C-reactive protein levels change in chronic dialysis patients prior to death. Kidney international. 2013;84(1):149-57.

16. Schols AM, Slangen J, Volovics L, Wouters EF. Weight loss is a reversible factor in the prognosis of chronic obstructive pulmonary disease. American journal of respiratory and critical care medicine. 1998;157(6 Pt 1):1791-7.

17. Shimizu T, Nagaoka U, Nakayama Y, Kawata A, Kugimoto C, Kuroiwa Y, et al. Reduction rate of body mass index predicts prognosis for survival in amyotrophic lateral sclerosis: a multicenter study in Japan. Amyotrophic lateral sclerosis : official publication of the World Federation of Neurology Research Group on Motor Neuron Diseases. 2012;13(4):363-6. 
18. Bamia C, Halkjaer J, Lagiou P, Trichopoulos D, Tjonneland A, Berentzen TL, et al. Weight change in later life and risk of death amongst the elderly: the European Prospective Investigation into Cancer and Nutrition-Elderly Network on Ageing and Health study. Journal of internal medicine. 2010;268(2):133-44.

19. Payette H, Coulombe C, Boutier V, Gray-Donald K. Weight loss and mortality among freeliving frail elders: a prospective study. The journals of gerontology Series A, Biological sciences and medical sciences. 1999;54(9):M440-5.

20. Newman AB, Yanez D, Harris T, Duxbury A, Enright PL, Fried LP, et al. Weight change in old age and its association with mortality. Journal of the American Geriatrics Society. 2001;49(10):1309-18.

21. Berentzen TL, Jakobsen MU, Halkjaer J, Tjonneland A, Overvad K, Sorensen TI. Changes in waist circumference and mortality in middle-aged men and women. PloS one. 2010;5(9).

22. Lee CG, Boyko EJ, Nielson CM, Stefanick ML, Bauer DC, Hoffman AR, et al. Mortality risk in older men associated with changes in weight, lean mass, and fat mass. Journal of the American Geriatrics Society. 2011;59(2):233-40.

23. Deutz NE, Bauer JM, Barazzoni R, Biolo G, Boirie Y, Bosy-Westphal A, et al. Protein intake and exercise for optimal muscle function with aging: recommendations from the ESPEN Expert Group. Clinical nutrition. 2014;33(6):929-36.

24. Ostergaard JN, Gronbaek M, Schnohr P, Sorensen TI, Heitmann BL. Combined effects of weight loss and physical activity on all-cause mortality of overweight men and women. International journal of obesity. 2010;34(4):760-9.

25. Kyle UG, Genton L, Slosman DO, Pichard C. Fat-free and fat mass percentiles in 5225 healthy subjects aged 15 to 98 years. Nutrition. 2001;17(7-8):534-41.

26. Kyle UG, Genton L, Karsegard L, Slosman DO, Pichard C. Single prediction equation for bioelectrical impedance analysis in adults aged 20--94 years. Nutrition. 2001;17(3):248-53. 
27. Genton L, Karsegard VL, Kyle UG, Hans DB, Michel JP, Pichard C. Comparison of four bioelectrical impedance analysis formulas in healthy elderly subjects. Gerontology. 2001;47(6):315-23.

28. Salvi F, Miller MD, Grilli A, Giorgi R, Towers AL, Morichi V, et al. A manual of guidelines to score the modified cumulative illness rating scale and its validation in acute hospitalized elderly patients. Journal of the American Geriatrics Society. 2008;56(10):1926-31.

29. Zekry D, Valle BH, Michel JP, Esposito F, Gold G, Krause KH, et al. Prospective comparison of six co-morbidity indices as predictors of 5 years post hospital discharge survival in the elderly. Rejuvenation research. 2010;13(6):675-82.

30. République et Canton de Genève. Etat civil. http://www.geneve.ch/etatcivil/deces. Accessed September 23, 2014.

31. Spoerri A, Zwahlen M, Egger M, Bopp M. The Swiss National Cohort: a unique database for national and international researchers. International journal of public health. 2010;55(4):239-42. 32. Benjamini Y, Hochberg Y. Controlling the false discovery rate: a practical and powerful approach to multiple testing. J R Stat Soc Series B Stat Methodol. 1995;57(1):289-300. 33. National Institutes of Health. Clinical guidelines on the identification, evaluation, and treatment of overweight and obesity in adults-the evidence report. Obes Res. 1998; Suppl 2:51S209S.

34. Gonzalez MC, Pastore CA, Orlandi SP, Heysmfield SB. Obesity paradox in cancer: new insights provided by body composition. The American journal of clinical nutrition. 2014.

35. Royston P, Sauerbrei W. A new measure of prognostic separation in survival data. Statistics in medicine. 2004;23(5):723-48.

36. Shea MK, Nicklas BJ, Houston DK, Miller ME, Davis CC, Kitzman DW, et al. The effect of intentional weight loss on all-cause mortality in older adults: results of a randomized controlled weight-loss trial. The American journal of clinical nutrition. 2011;94(3):839-46. 
37. Zimmermann E, Berentzen TL, Angquist L, Holst C, Sorensen TI. Long-term weight changes in obese young adult men and subsequent all-cause mortality. International journal of obesity. 2013;37(7):1020-5.

38. Sorensen TI, Rissanen A, Korkeila M, Kaprio J. Intention to lose weight, weight changes, and 18-y mortality in overweight individuals without co-morbidities. PLoS medicine. 2005;2(6):e171. 39. Berentzen T, Sorensen TI. Effects of intended weight loss on morbidity and mortality: possible explanations of controversial results. Nutrition reviews. 2006;64(11):502-7.

40. Harrington M, Gibson S, Cottrell RC. A review and meta-analysis of the effect of weight loss on all-cause mortality risk. Nutrition research reviews. 2009;22(1):93-108. 


\section{FIGURE}

Figure 1: Kaplan-Meier curves showing the probability of survival according to categories of BMI (A), FFMI (B) and FMI changes (C) in women and men. ".... " indicates maintenance, "

" indicates gain and " " " idelicates loss. The log rank tests were $\mathrm{p}=0.131$ for BMI changes, 0.191 for FFMI changes and $\mathrm{p}=0.051$ for FMI changes for women and $\mathrm{p}=0.025$ for BMI changes, 0.019 for FFMI changes and $\mathrm{p}=0.123$ for FMI change for men. 


\section{Figure 1}

Women

A.

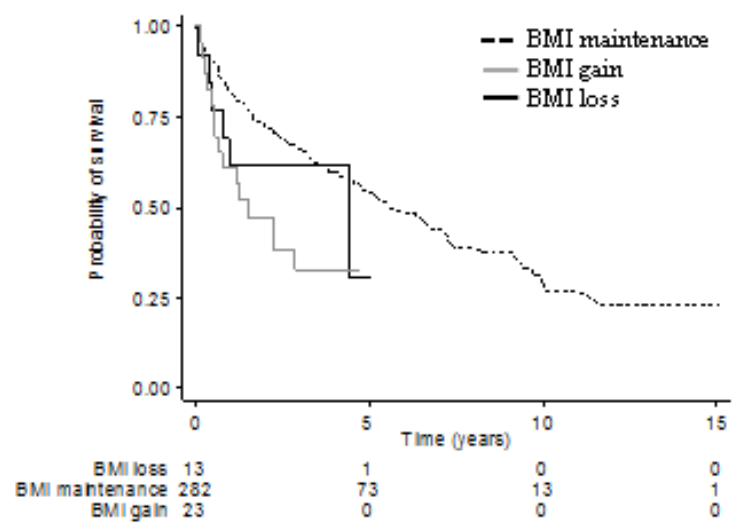

B.

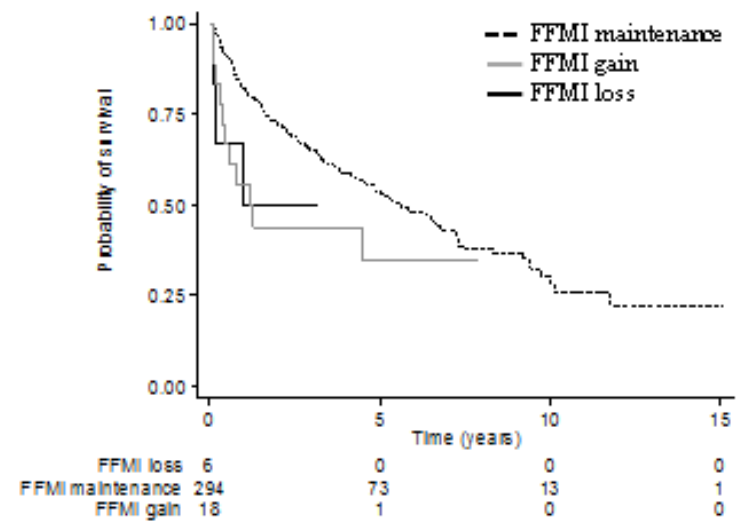

C.

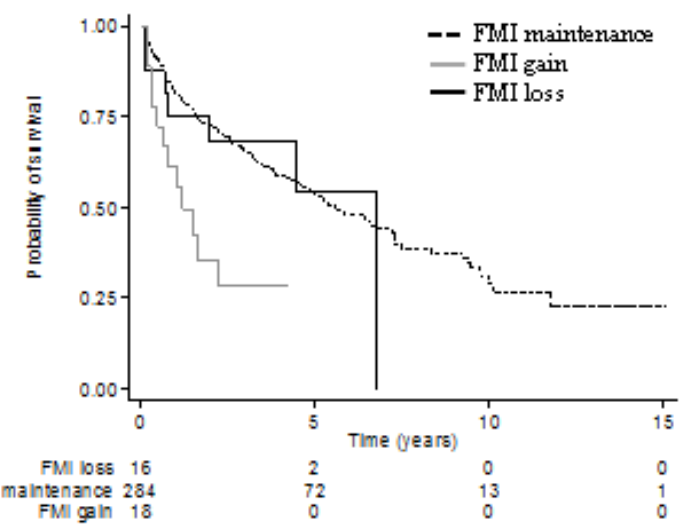

Men
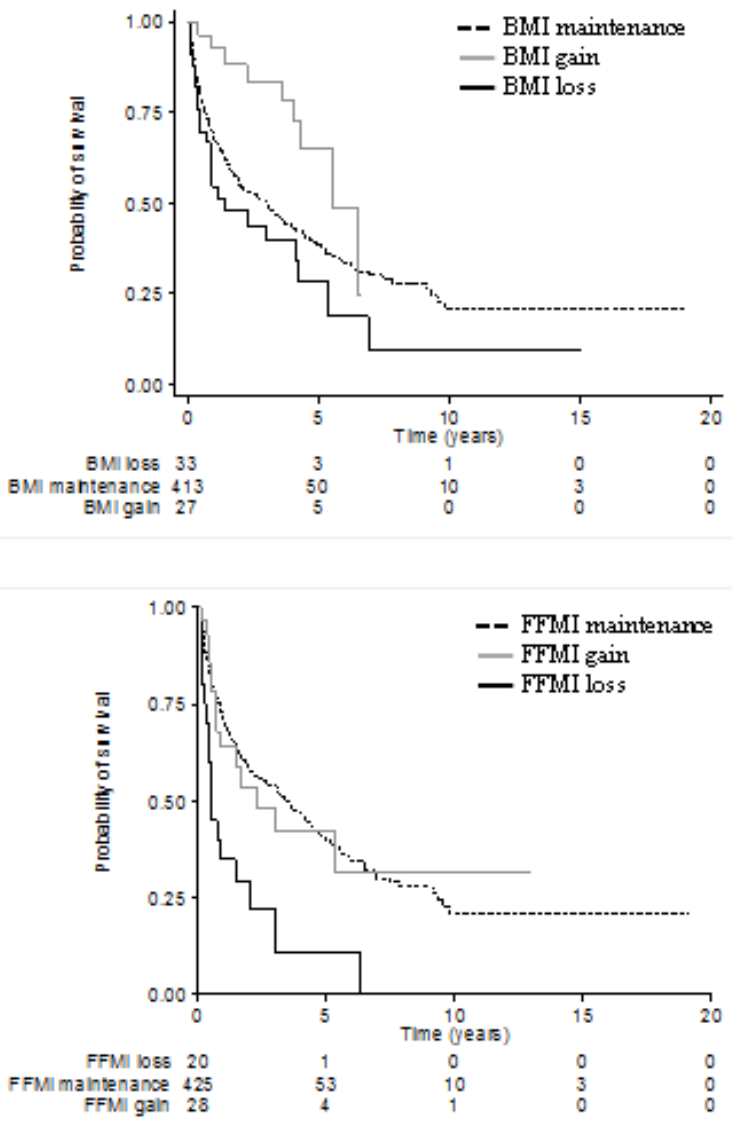
Table 1: Characteristics of the study population at the last BIA measurement

\begin{tabular}{|c|c|c|c|c|c|c|c|c|c|c|c|c|c|}
\hline & \multicolumn{4}{|c|}{ All } & \multicolumn{4}{|c|}{ Women } & \multicolumn{4}{|c|}{ Men } & \multirow[b]{2}{*}{$p^{*}$} \\
\hline & n & $\%$ & mean & SD & $\mathbf{n}$ & $\%$ & mean & SD & $\mathbf{n}$ & $\%$ & mean & SD & \\
\hline \multicolumn{14}{|l|}{ Continuous variables } \\
\hline Last age [yrs] & 791 & 100 & 75.3 & 6.8 & 318 & 100 & 76.0 & 7.1 & 473 & 100 & 74.8 & 6.5 & 0.022 \\
\hline Last CIRS score & 791 & 100 & 14.1 & 7.4 & 318 & 100 & 12.1 & 7.1 & 473 & 100 & 15.5 & 7.3 & $<0.001$ \\
\hline Last height $[\mathrm{cm}]$ & 791 & 100 & 166.2 & 9.5 & 318 & 100 & 158.7 & 7.1 & 473 & 100 & 171.2 & 7.5 & $<0.001$ \\
\hline Last weight $[\mathrm{kg}]$ & 791 & 100 & 68.2 & 17.3 & 318 & 100 & 62.4 & 18.3 & 473 & 100 & 72.1 & 15.5 & $<0.001$ \\
\hline Last BMI $\left[\mathrm{kg} / \mathrm{m}^{2}\right]$ & 791 & 100 & 24.6 & 6.0 & 318 & 100 & 24.8 & 7.1 & 473 & 100 & 24.6 & 5.0 & 0.674 \\
\hline Last FFMI $\left[\mathrm{kg} / \mathrm{m}^{2}\right]$ & 791 & 100 & 16.9 & 3.1 & 318 & 100 & 15.4 & 3.1 & 473 & 100 & 17.9 & 2.8 & $<0.001$ \\
\hline Last FMI $\left[\mathrm{kg} / \mathrm{m}^{2}\right]$ & 791 & 100 & 7.8 & 3.9 & 318 & 100 & 9.4 & 4.6 & 473 & 100 & 6.7 & 3.0 & $<0.001$ \\
\hline $\begin{array}{l}\text { Follow-up since last BIA } \\
\text { until censored [yrs] }\end{array}$ & 791 & 100 & 3.0 & 3.0 & 364 & 100 & 3.6 & 3.1 & 473 & 100 & 2.6 & 2.8 & $<0.001$ \\
\hline Age at death [yrs] & 425 & 58 & 77.8 & 7.8 & 159 & 44 & 79.2 & 8.5 & 266 & 56 & 77.0 & 7.3 & 0.007 \\
\hline $\begin{array}{l}\text { Follow-up since last BIA } \\
\text { until death [yrs] }\end{array}$ & 425 & 58 & 2.0 & 2.2 & 159 & 44 & 2.5 & 2.6 & 266 & 56 & 1.6 & 1.9 & $<0.001$ \\
\hline Baseline age [yrs] & 791 & 100 & 72.5 & 6.2 & 318 & 100 & 76.0 & 7.1 & 473 & 100 & 72.1 & 6.0 & 0.082 \\
\hline Baseline CIRS score & 784 & 99 & 12.0 & 7.1 & 314 & 99 & 12.1 & 7.1 & 470 & 99 & 13.1 & 7.0 & $<0.001$ \\
\hline Baseline height $[\mathrm{cm}]$ & 791 & 100 & 166.8 & 9.4 & 318 & 100 & 158.7 & 7.1 & 473 & 100 & 171.7 & 7.4 & $<0.001$ \\
\hline Baseline weight $[\mathrm{kg}]$ & 791 & 100 & 69.7 & 17.9 & 318 & 100 & 62.4 & 18.3 & 473 & 100 & 73.8 & 16.0 & $<0.001$ \\
\hline Baseline BMI $\left[\mathrm{kg} / \mathrm{m}^{2}\right]$ & 791 & 100 & 25.0 & 6.0 & 318 & 100 & 24.8 & 7.1 & 473 & 100 & 25.0 & 5.1 & 0.967 \\
\hline Baseline FFMI $\left[\mathrm{kg} / \mathrm{m}^{2}\right]$ & 791 & 100 & 17.0 & 3.2 & 318 & 100 & 15.4 & 3.1 & 473 & 100 & 18.1 & 2.8 & $<0.001$ \\
\hline Baseline FMI $\left[\mathrm{kg} / \mathrm{m}^{2}\right]$ & 791 & 100 & 8.0 & 4.0 & 318 & 100 & 9.4 & 4.6 & 473 & 100 & 6.9 & 3.0 & $<0.001$ \\
\hline \multicolumn{14}{|l|}{ Categorical variables } \\
\hline Last BMI $\left[\mathrm{kg} / \mathrm{m}^{2}\right]$ & & & & & & & & & & & & & 0.066 \\
\hline$<18.5$ & 97 & 12 & 16.6 & 1.3 & 50 & 16 & 16.5 & 1.3 & 47 & 10 & 16.6 & 1.4 & \\
\hline $18.5-24.9$ & 353 & 45 & 21.9 & 1.8 & 139 & 44 & 21.8 & 1.7 & 214 & 45 & 22.0 & 1.9 & \\
\hline$>25$ & 341 & 43 & 29.8 & 5.1 & 129 & 41 & 31.1 & 6.7 & 212 & 45 & 29.0 & 3.5 & \\
\hline Last FFMI $\left[\mathrm{kg} / \mathrm{m}^{2}\right]^{1}$ & & & & & & & & & & & & & 0.283 \\
\hline
\end{tabular}




\begin{tabular}{|c|c|c|c|c|c|c|c|c|c|c|c|c|c|}
\hline No sarcopenia & 399 & 50 & 19.1 & 2.5 & 153 & 48 & 17.7 & 2.7 & 246 & 52 & 19.9 & 1.9 & \\
\hline Sarcopenia & 392 & 50 & 14.6 & 1.8 & 165 & 52 & 13.2 & 1.4 & 227 & 48 & 15.6 & 1.5 & \\
\hline Last FMI $\left[\mathrm{kg} / \mathrm{m}^{2}\right]^{2}$ & & & & & & & & & & & & & 0.001 \\
\hline No obesity & 308 & 39 & 4.8 & 1.8 & 146 & 46 & 6.0 & 1.7 & 162 & 34 & 3.7 & 1.1 & \\
\hline Obesity & 483 & 61 & 9.7 & 3.7 & 172 & 54 & 12.3 & 4.2 & 311 & 66 & 8.3 & 2.4 & \\
\hline
\end{tabular}

BIA: bioimpedance analysis, CIRS: Cumulative Illness Rating Scale, BMI: body mass index, FM: fat mass, FMI: fat mass index, FFMI: fat-free mass index

* $p$ : unpaired t-test for continuous data between men and women and Mann-Whitney $\mathrm{U}$ test for categorical data comparison between men and women

${ }^{1}$ Sarcopenia was defined as FFMI $<15.1 \mathrm{~kg} / \mathrm{m}^{2}$ for women and $<17.5 \mathrm{~kg} / \mathrm{m}^{2}$ for men (34)

${ }^{2}$ Obesity was defined as FMI $>8.2 \mathrm{~kg} / \mathrm{m}^{2}$ for women and $>5.2 \mathrm{~kg} / \mathrm{m}^{2}$ in men (34) 
Table 2: Categories of body mass index, fat mass index and fat-free mass index changes, calculated for one month

\begin{tabular}{|c|c|c|c|c|c|c|c|c|c|c|c|c|c|c|c|c|}
\hline & \multicolumn{5}{|c|}{ All $(n=791)$} & \multicolumn{4}{|c|}{ Women $(n=318)$} & \multicolumn{6}{|c|}{$\operatorname{Men}(n=473)$} & \multirow[b]{2}{*}{$p^{*}$} \\
\hline & $\mathbf{n}$ & $\%$ & mean & SD & $\min , \max$ & $\mathbf{n}$ & $\%$ & mean & SD & $\min , \max$ & $\mathbf{n}$ & $\%$ & mean & SD & $\min , \max$ & \\
\hline BMI change $\left[\mathrm{kg} / \mathrm{m}^{2} / \mathrm{month}\right]$ & & & & & & & & & & & & & & & & 0.081 \\
\hline Maintenance & 695 & 88 & -0.1 & 0.5 & $-3.4,2.1$ & 282 & 89 & -0.1 & 0.5 & $-3.2,1.7$ & 413 & 87 & -0.1 & 0.5 & $-3.4,2.1$ & \\
\hline Gain & 50 & 6 & 0.3 & 0.4 & $0.1,1.9$ & 23 & 7 & 0.3 & 0.3 & $0.1,1.1$ & 27 & 6 & 0.3 & 0.5 & $0.1,1.9$ & \\
\hline Loss & 46 & 6 & -0.3 & 0.3 & $-1.2,-0.1$ & 13 & 4 & -0.3 & 0.3 & $-1.1,-0.1$ & 33 & 7 & -0.3 & 4.0 & $-0.3,-0.1$ & \\
\hline FFMI change $\left[\mathrm{kg} / \mathrm{m}^{2} / \mathrm{month}\right]$ & & & & & & & & & & & & & & & & 0.350 \\
\hline Maintenance & 719 & 91 & -0.1 & 0.5 & $-6.1,2.9$ & 294 & 92 & -0.1 & 0.5 & $-6.1,2.9$ & 425 & 90 & -0.1 & 0.4 & $-4.3,2.2$ & \\
\hline Gain & 46 & 6 & 0.3 & 0.7 & $0.1,-4.5$ & 18 & 6 & 0.3 & 1.0 & $0.1,4.5$ & 28 & 6 & 0.2 & 0.4 & $0.1,1.6$ & \\
\hline Loss & 26 & 3 & -0.3 & 0.4 & $-1.8,-0.1$ & 6 & 2 & -0.5 & 0.7 & $-1.8,-0.1$ & 20 & 4 & -0.2 & 0.2 & $-0.7,-0.1$ & \\
\hline FMI change $\left[\mathrm{kg} / \mathrm{m}^{2} / \mathrm{month}\right]$ & & & & & & & & & & & & & & & & 0.936 \\
\hline Maintenance & 697 & 88 & -0.1 & 0.4 & $-2.9,4.4$ & 284 & 89 & -0.1 & 0.4 & $-2.4,4.4$ & 413 & 87 & -0.1 & 0.4 & $-2.9,3.2$ & \\
\hline Gain & 49 & 6 & 0.2 & 0.2 & $0.1,0.9$ & 18 & 6 & 0.2 & 0.2 & $0.1,0.9$ & 31 & 7 & 0.2 & 0.2 & $0.1,0.9$ & \\
\hline Loss & 45 & 6 & -0.2 & 0.6 & $-4.2,-0.1$ & 16 & 5 & -0.4 & 1.0 & $-4.2,-0.1$ & 29 & 6 & -0.2 & 0.2 & $-0.7,-0.1$ & \\
\hline
\end{tabular}

BMI: body mass index, FMI: fat mass index, FFMI: fat-free mass index

* $p$ : unpaired t-test for continuous data between men and women and Mann-Whitney $\mathrm{U}$ test for categorical data comparison between men and women

${ }^{1}$ Sarcopenia was defined as FFMI $<15.1 \mathrm{~kg} / \mathrm{m}^{2}$ for women and $<17.5 \mathrm{~kg} / \mathrm{m}^{2}$ for men (34)

${ }^{2}$ Obesity was defined as FMI $>8.2 \mathrm{~kg} / \mathrm{m}^{2}$ for women and $>5.2 \mathrm{~kg} / \mathrm{m}^{2}$ in men (34) 
Table 3: Multiple Cox regressions evaluating the association between body composition changes and mortality $(n=791)$

\begin{tabular}{|c|c|c|c|c|c|c|c|c|c|c|c|c|c|c|c|}
\hline \multirow[b]{2}{*}{ Variables } & \multicolumn{3}{|c|}{ Model 1} & \multicolumn{3}{|c|}{ Model 2} & \multicolumn{3}{|c|}{ Model 3} & \multicolumn{3}{|c|}{ Model 4} & \multicolumn{3}{|c|}{ Model 5} \\
\hline & HR & $95 \% \mathrm{CI}$ & $\mathbf{p}$ & HR & $95 \% \mathrm{CI}$ & $\mathbf{p}$ & HR & $95 \% \mathrm{CI}$ & $\mathbf{p}$ & HR & $95 \% \mathrm{CI}$ & $\mathbf{p}$ & HR & $95 \% \mathrm{CI}$ & $\mathbf{P}$ \\
\hline & & & $<0.001$ & & & $<0.001$ & & & $<0.001$ & & & $<0.001$ & & & $<0.001$ \\
\hline \multicolumn{16}{|c|}{ BMI change $\left[\mathrm{kg} / \mathrm{m}^{2} /\right.$ year $]$} \\
\hline Maintenance & 1.00 & & & & & & & & & 1.00 & & & & & \\
\hline Gain & 0.89 & $0.59,1.36$ & 0.612 & & & & & & & 0.95 & $0.62,1.45$ & 0.814 & & & \\
\hline Loss & 1.12 & $0.76,1.64$ & 0.562 & & & & & & & 1.10 & $0.75,1.61$ & 0.627 & & & \\
\hline \multicolumn{16}{|c|}{ FFMI change $\left[\mathrm{kg} / \mathrm{m}^{2} /\right.$ year] } \\
\hline Maintenance & & & & 1.00 & & & & & & & & & 1.00 & & \\
\hline Gain & & & & 1.17 & $0.79,1.75$ & 0.438 & & & & & & & 1.17 & $0.77,1.77$ & 0.455 \\
\hline Loss & & & & 2.02 & $1.28,3.19$ & 0.002 & & & & & & & 1.68 & $1.04,2.70$ & 0.032 \\
\hline \multicolumn{16}{|c|}{ FMI change $\left[\mathrm{kg} / \mathrm{m}^{2} /\right.$ year $]$} \\
\hline Maintenance & & & & & & & 1.00 & & & & & & 1.00 & & \\
\hline Gain & & & & & & & 1.05 & $0.70,1.58$ & 0.805 & & & & 0.90 & $0.59,1.39$ & 0.645 \\
\hline Loss & & & & & & & 0.87 & $0.57,1.34$ & 0.536 & & & & 0.82 & $0.53,1.28$ & 0.379 \\
\hline \multicolumn{16}{|l|}{ Sex } \\
\hline Women & 1.00 & & & 1.00 & & & 1.00 & & & 1.00 & & & 1.00 & & \\
\hline Men & 1.19 & $0.97,1.46$ & 0.091 & 1.18 & $0.97,1.45$ & 0.106 & 1.20 & $0.98,1.46$ & 0.085 & 1.29 & $1.04,1.58$ & 0.018 & 1.27 & $1.04,1.57$ & 0.022 \\
\hline Last age [yrs] & 1.01 & $1.00,1.03$ & 0.140 & 1.01 & $1.00,1.03$ & 0.110 & 1.01 & $1.00,1.03$ & 0.113 & 1.01 & $1.00,1.03$ & $<0.001$ & 1.01 & $1.00,1.03$ & 0.001 \\
\hline Last CIRS [score] & 1.08 & $1.06,1.09$ & $<0.001$ & 1.08 & $1.06,1.09$ & $<0.001$ & 1.08 & $1.06,1.09$ & $<0.001$ & 1.08 & $1.06,1.09$ & $<0.001$ & 1.07 & $1.06,1.09$ & $<0.001$ \\
\hline \multicolumn{16}{|l|}{ Last BMI $\left[\mathrm{kg} / \mathrm{m}^{2}\right]$} \\
\hline$<18.5$ & & & & & & & & & & 1.10 & $0.75,1.61$ & & & & \\
\hline $18.5-24.9$ & & & & & & & & & & 1.00 & & & & & \\
\hline$\geq 25.0$ & & & & & & & & & & 0.95 & $0.62,1.45$ & & & & \\
\hline \multicolumn{16}{|l|}{ Last FFMI $\left[\mathrm{kg} / \mathrm{m}^{2}\right]$} \\
\hline No sarcopenia & & & & & & & & & & & & & 1.00 & & \\
\hline Sarcopenia & & & & & & & & & & & & & 1.68 & $1.35,2.11$ & $<0.001$ \\
\hline \multicolumn{16}{|l|}{ Last FMI $\left[\mathrm{kg} / \mathrm{m}^{2}\right]$} \\
\hline No obesity & & & & & & & & & & & & & 1.00 & & \\
\hline Obesity & & & & & & & & & & & & & 0.80 & $0.64,0.99$ & 0.045 \\
\hline
\end{tabular}

BMI: body mass index, FFMI: fat free mass index, FMI: fat mass index, CIRS: Cumulative Illness Rating Scale 